О НЕОБХОДИМОСТИ ИСПОЛЬЗОВАНИЯ СРЕДСТВ ИНДИВИДУАЛЬНОЙ ЗАЩИТЫ ОРГАНОВ ДЫХАНИЯ В РАБОТЕ СВАРЩИКА

\title{
ABOUT THE NEED TO USE PERSONAL RESPIRATORY PROTECTION IN THE WORK OF A WELDER
}

\author{
Г.А. Султанова, С.А. Кинев, В.Р. Файрушина
}

Уфимский государственный нефтяной технический университет, Уфа, Российская Федерация

\author{
Guzel A. Sultanova, Sergey A. Kinev, Valeriya R. Fairushina \\ Ufa State Petroleum Technological University, \\ Ufa, Russian Federation \\ e-mail: otsk@ rusoil.net
}

\begin{abstract}
Аннотация. Сварочные процессы с использованием дуговой сварки широко применяются в различных отраслях современной промышленности ввиду своей практической незаменимости. Одним из недостатков дуговых процессов сварки является низкая экологичность. В настоящее время значительное количество людей, занятых сварочными работами, подвергаются воздействию различных опасных производственных факторов. Актуальной задачей для промышленной безопасности и охраны труда является внедрение современных методов оценки вредных факторов при сварочных работах, а также использование эффективных систем вентиляции и средств индивидуальной защиты.
\end{abstract}

К наиболее вредным факторам при сварке относится выделение сварочного дыма. В его состав входит вещество первого класса опасности озон, под действием которого у сварщика развиваются различные 
заболевания. Этот газ возникает при воздействии ультрафиолетового излучения на кислород в воздухе, а также при сварке светоотражающих поверхностей, таких как нержавеющая сталь и алюминий.

В статье представлены результаты исследования, в котором была измерена концентрация озона при различных условиях и видах сварки. Проанализированы разные виды средств индивидуальной защиты органов дыхания. На основе полученных данных сделаны выводы о том, что наибольшие концентрации выделяемого озона наблюдаются при сварке в среде защитных газов.

В данной работе для эффективной защиты от вредного воздействия озона предлагаются современные маски с автономными фильтрующими блоками подачи воздуха, а также с ионообменной смолой.

Проведенные авторами опросы среди сварщиков показали пренебрежение защитой органов дыхания в процессе работы на производстве, опрос учащихся колледжей по профессии «Сварщик» также показал отсутствие понимания необходимости в защите органов дыхания.

Abstract. Welding processes using arc welding are widely used in various branches of modern industry due to their practical indispensability. One of the drawbacks of arc welding processes is low environmental friendliness, and at present a significant number of people engaged in welding work are exposed to various hazardous production factors. An urgent task for industrial safety and labor protection is the introduction of modern methods for assessing harmful factors during welding, as well as the use of effective ventilation systems and personal protective equipment.

The most harmful factors during welding are the emission of welding fumes. It contains a substance of the first hazard class - ozone, under the influence of which the welder develops various diseases. This gas occurs when UV radiation is exposed to oxygen in the air, and when welding reflective surfaces such as stainless steel and aluminum. 
The article discusses a study that measured the concentration of ozone under various conditions and types of welding. Various types of personal protective equipment for the respiratory organs are analyzed. Based on the data obtained, it was concluded that the highest concentrations of released ozone are observed during welding in a shielded gas environment.

In this work, for effective protection from the harmful effects of ozone, modern masks with self-contained filtering air supply units, as well as with ionexchange resin, are proposed.

Surveys conducted by the authors among welders showed disregard for respiratory protection during work in production, a survey of college students by profession «Welder» also showed a lack of understanding of the need for respiratory protection.

Ключевые слова: сварочный процесс; опасные факторы; озон; промышленная безопасность; средства индивидуальной защиты органов дыхания

Key words: welding process; hazards; ozone; industrial safety; personal respiratory protection

В настоящее время невозможно представить современное производство без сварочных технологий и процессов. Сварка играет важную роль в различных отраслях индустрии и промышленности, она применяется для создания новых сооружений, конструкций и механизмов, а также для их ремонта. Общепризнанным является превосходство сварных конструкций над другими видами изделий за счет экономичного расхода металла, сокращения времени изготовления, упрощения оборудования, понижения затрачиваемого труда. В некоторых отраслях трудоемкость сварочных работ доходит до $40 \%$ от всей трудоемкости изготовления. Также сварочные процессы широко распространены в строительстве и ремонте нефтехранилищ и трубопроводов. 
Всемирная организация здравоохранения и международная научномедицинская общественность причисляют сварку к числу работ опасных для здоровья. Согласно клинике института медицины труда, средний стаж сварщиков с инвалидностью по профессиональному заболеванию составляет 18 лет, в том числе у работающих на полуавтоматах - 14 лет, у работающих с ручной дуговой сваркой - 21 год [1].

Во время сварочного процесса возникает ряд факторов, оказывающее вредное воздействие не только на самого сварщика, но и на людей, находящихся поблизости.

Одним из этих факторов является наполнение помещения сварочным дымом, представляющим собой мельчайшие частицы сварочных аэрозолей. Они, в свою очередь, являются совокупностью мельчайших частиц, образованные при конденсации паров шлака, расплавленного металла и покрытия электродов.

Состав сварочных аэрозолей зависит от свариваемых металлов и сварочных материалов, вентиляции, от технологии и режимов сварки. Например, в составе могут быть такие вредные элементы, как окислы марганца, которые способны вызвать заболевания крови, нервной системы, легких; различные соединения хрома, приводящие к заболеваниям пищеварительных органов, к головным болям и малокровию; окись титана, плохо влияющая на легкие; соединения кремния, в результате вдыхания которой возникает силикоз [2].

Помимо аэрозолей в состав дыма входят и вредные газы, такие как озон, который возникает при воздействии ультрафиолетового излучения на кислород в воздухе. Молекулы кислорода расщепляются на атомы кислорода и оттуда свободные атомы соединяются с другой молекулой кислорода с образованием озона. Также при сварке светоотражающих поверхностей, таких как нержавеющая сталь и алюминий, образуется большое количество озона [3]. 
Озон - это высокотоксичный и химически активный газ, который относят к веществам первого класса опасности. Он, как сильный окислитель, даже полезен в малых дозах, однако при превышении своей предельно допустимой концентрации, равной 0,1 мг/м ${ }^{3}$, наносит большой вред на человека.

Озон вызывает сердечнососудистые заболевания, сильную усталость, психические расстройства. У рабочих, подвергающихся длительному его воздействию, наблюдаются ухудшение памяти, головные боли, вегетативные нарушения, заболевания легких, раковые заболевания, мужское бесплодие.

Самые высокие концентрации озона образуются в непосредственной близости от дуги, но он также может возникать на некотором расстоянии от дуги, но в меньших концентрациях.

Для того чтобы установить, при каких видах сварки и при каких условиях может образоваться озон, было проведено исследование 34 рабочих мест на 8 предприятиях.

При помощи газоанализатора «Drager X-am 5000» были сделаны замеры концентраций озона на рабочих местах сварщиков, при этом условия работы на этих местах были разными в зависимости от вентиляции, вида сварки, рода материала, режима работы.

Результаты измерений приведены в таблице 1.

Стоит отметить, что замеры происходили в зоне дыхания сварщика либо с максимальным приближением к ней устройства, то есть при работе стоя на высоте 1,5 м от пола, или при работе сидя на высоте 1 м. 
Таблица 1. Результаты измерений

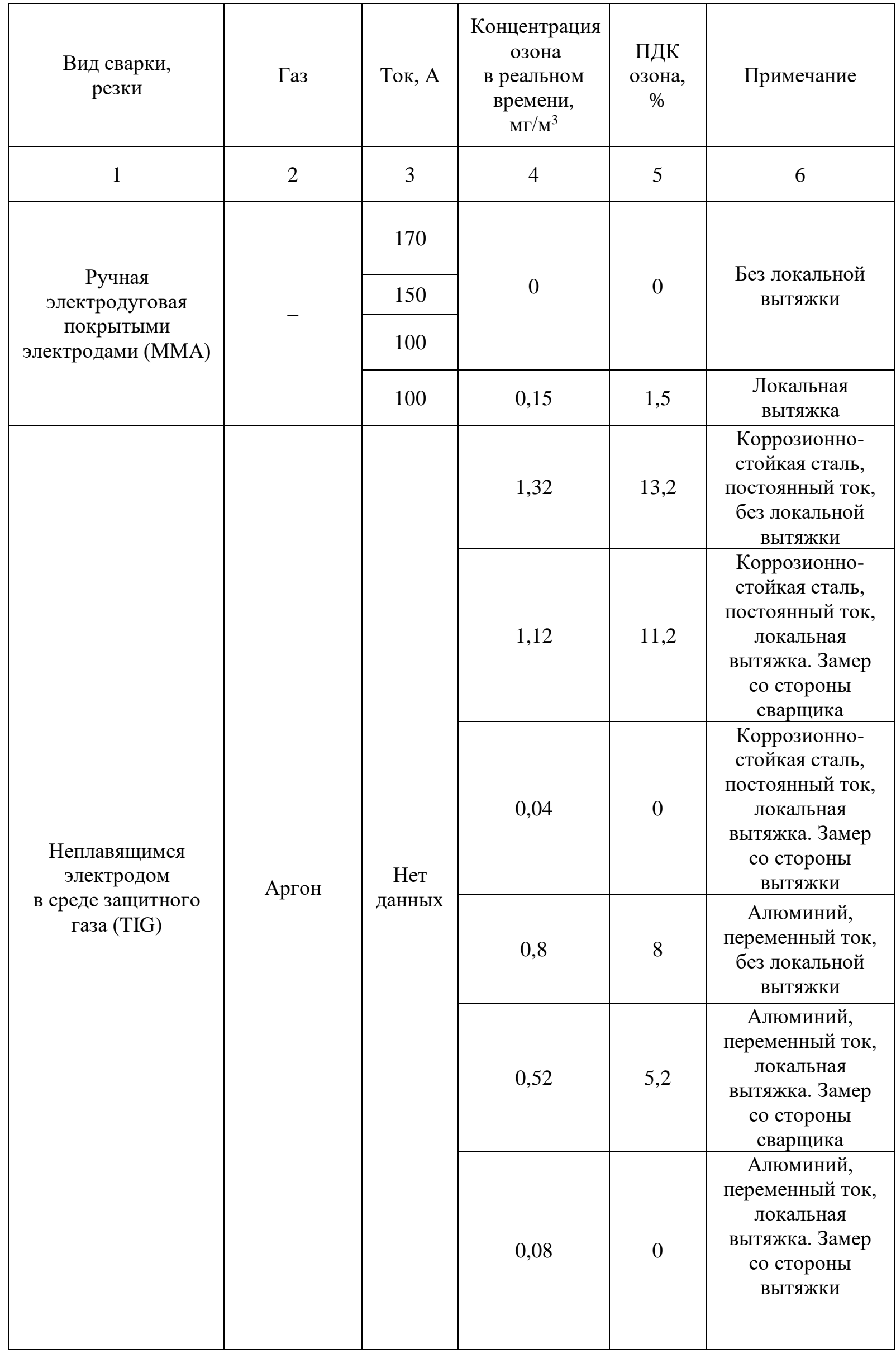


Продолжение таблицы 1

\begin{tabular}{|c|c|c|c|c|c|}
\hline 1 & 2 & 3 & 4 & 5 & 6 \\
\hline \multirow{16}{*}{$\begin{array}{c}\text { Полуавтоматическая } \\
\text { (MAG) }\end{array}$} & \multirow{16}{*}{$\begin{array}{c}\text { Углекислый } \\
\text { газ }\end{array}$} & 400 & 0,8 & 8 & \multirow{3}{*}{$\begin{array}{c}\text { Без локальной } \\
\text { вытяжки }\end{array}$} \\
\hline & & 360 & 0,5 & 5 & \\
\hline & & 320 & 0,16 & 1,6 & \\
\hline & & 300 & 0,1 & 1 & \multirow{2}{*}{$\begin{array}{c}\text { Локальная } \\
\text { вытяжка }\end{array}$} \\
\hline & & 270 & 0,16 & 1,6 & \\
\hline & & 260 & 0,3 & 3 & $\begin{array}{c}\text { Железо, } \\
\text { локальная } \\
\text { вытяжка }\end{array}$ \\
\hline & & 250 & 0,4 & 4 & $\begin{array}{c}\text { Без локальной } \\
\text { вытяжки }\end{array}$ \\
\hline & & 250 & 0,1 & 1 & $\begin{array}{c}\text { Локальная } \\
\text { вытяжка }\end{array}$ \\
\hline & & 250 & 2,2 & 22 & \multirow{5}{*}{$\begin{array}{c}\text { Без локальной } \\
\text { вытяжки }\end{array}$} \\
\hline & & 250 & 0,9 & 9 & \\
\hline & & 250 & 0,8 & 8 & \\
\hline & & 250 & 1,5 & 15 & \\
\hline & & 250 & 0,9 & 9 & \\
\hline & & 230 & 0,28 & 2,8 & $\begin{array}{c}\text { Железо, } \\
\text { локальная } \\
\text { вытяжка }\end{array}$ \\
\hline & & 220 & 0,7 & 7 & $\begin{array}{c}\text { Железо, } \\
\text { локальная } \\
\text { вытяжка. Много } \\
\text { озона от рядом } \\
\text { находящейся } \\
\text { газопламенной } \\
\text { резки }\end{array}$ \\
\hline & & 180 & 0,28 & 2,8 & $\begin{array}{c}\text { Без локальной } \\
\text { вытяжки }\end{array}$ \\
\hline $\begin{array}{c}\text { Машина } \\
\text { термической резки }\end{array}$ & $\begin{array}{l}\text { Кислород, } \\
\text { пропан }\end{array}$ & - & 0,6 & 6 & $\begin{array}{c}\text { Без локальной } \\
\text { вытяжки }\end{array}$ \\
\hline \multirow{2}{*}{$\begin{array}{c}\text { Машина } \\
\text { термической сварки }\end{array}$} & \multirow{2}{*}{$\begin{array}{c}\text { Кислород, } \\
\text { ацетилен }\end{array}$} & \multirow{2}{*}{-} & 0,06 & 0,6 & \multirow{2}{*}{$\begin{array}{c}\text { Встроенная } \\
\text { вытяжка }\end{array}$} \\
\hline & & & 0 & 0 & \\
\hline \multirow{2}{*}{ Газопламенная резка } & \multirow{2}{*}{$\begin{array}{l}\text { Кислород, } \\
\text { пропан }\end{array}$} & \multirow{2}{*}{-} & 0 & 0 & \multirow{2}{*}{$\begin{array}{c}\text { Без локальной } \\
\text { вытяжки }\end{array}$} \\
\hline & & & 0,4 & 4 & \\
\hline \multirow{3}{*}{ Газопламенная резка } & \multirow{3}{*}{$\begin{array}{l}\text { Кислород, } \\
\text { пропан }\end{array}$} & \multirow{3}{*}{-} & 0,7 & 7 & \multirow{3}{*}{$\begin{array}{c}\text { Встроенная } \\
\text { вытяжка }\end{array}$} \\
\hline & & & 0,1 & 1 & \\
\hline & & & 0,06 & 0,6 & \\
\hline
\end{tabular}

Данные, полученные во время исследования, говорят о том, что во время аргонодуговой сварки концентрация озона намного превышает предельно допустимую, наибольшая - составляет 1,32 мг/м³. Она, при данном виде сварки, зависела от области проведения замера, а также от наличия местной 
вытяжки и ее эффективности. При аргонодуговой сварке выделяется меньше дыма, а это приводит к тому, что ультрафиолетовые лучи лучше распространяются, что способствуют к большему образованию озона. Также стоит учесть, что озон является неустойчивым газом, что приводит к тому, что дым и пыль способствуют его разложению до кислорода.

При полуавтоматической сварке в среде углекислого газа также обнаружена высокая концентрация озона, при этом зависимость от силы сварочного тока не установлена.

Озон практически не обнаружен при ручной дуговой сварке. Можно предположить, что это из-за работы на низких для этого типа сварки токах, либо из-за высокого количества частиц пыли.

Известно также, что озон, образованный в большом количестве на рабочем месте, оказывает влияние и на другие ближайшие рабочие места [4]. Снизить уровень выбросов помогает добавление в защитный газ химического вещества, которое вступает в реакцию с озоном и увеличивает скорость его разложения. В этом случае к аргону обычно добавляют относительно небольшие концентрации водорода или оксида азота.

На некоторых предприятиях не уделяется должное внимание негативным влияниям сварочных газов, а также надобности защиты от них, поэтому рабочие используют лишь противоаэрозольную респираторную защиту, упуская из виду необходимость защиты от озона. Это происходит из-за того, что во время оценки условий труда озон иногда не выявляется. Эксперименты показали, что концентрация озона, измеренная в течение первой минуты сварки, сразу достигает пика, который спадает через несколько секунд, а затем остается постоянным на уровне фона от 40 \% до $60 \%$ от наибольшего значения, поэтому приборы не успевают зафиксировать высокую концентрацию озона.

Несмотря на высокий показатель заболеваемости сварщиков, на предприятиях не проводят полной систематизированной оценки профессионального риска. Одной из наиболее актуальных задач в 
промышленной безопасности является внедрение современных методов оценки вредных факторов при сварочных процессах, а также использование эффективных систем вентиляции и средств индивидуальной защиты (СИЗ).

При естественной вентиляции в некоторых рабочих помещениях проветривание происходит через открытые двери и окна, что является экономичным, но не эффективным способом снижения концентрации вредных веществ и газов.

Местная вытяжная вентиляция удаляет вредные вещества прямо от места, где они образуются, предотвращая их распространение по цеху и проникновение в зоны дыхания, находящихся рядом. Для эффективного улавливания дыма и вредных частиц необходимо, чтобы расход воздуха, проходящего через воздухоприемные воронки, должен быть 600-100 м³/ч.

Также существуют передвижные фильтровентиляционные агрегаты, удаляющие загрязненный воздух из рабочего места, очищающие его и возвращающие обратно. Большим достоинством является отсутствие монтажных работ, возможность свободно перемещаться по цеху, высокая степень улавливания опасных веществ, экономия энергии благодаря рециркуляции воздуха. Однако фильтрующие элементы данного агрегата необходимо периодически очищать или менять на новые [3].

Не всегда установленная на предприятии вентиляция позволяет достигнуть безопасного уровня концентрации, поэтому сварщикам необходимо дополнительно использовать СИЗ. Технический Регламент Таможенного союза 019/2011«О безопасности СИЗ», несмотря на высокое воздействие вредных веществ на органы дыхания, не описывает специальные требования к средствам индивидуальной защиты органов дыхания рабочих (СИЗОД). Также в Типовых нормах бесплатной выдачи сертифицированных СИЗ не указывается, какими именно средствами индивидуальной защиты должен быть обеспечен сварщик. Это означает, что имеющиеся на рабочем месте работника СИЗ не дают гарантии 
безопасности для него, так как не учтены особенности сварочного процесса и защитные свойства СИЗОД.

Более эффективным, по сравнению с респираторами, являются специальные защитные полумаски из изолирующих материалов, оснащенных фильтрами от вредных газов и дымов. Данный вид СИЗОД удобен плотным прилеганием к лицу сварщика, а также меньшим временем на обучение правильному использованию. Также полумаски, по сравнению с респираторами, экономически более выгодные из-за больших ресурсов фильтрующих элементов.

Однако при сварочном процессе под такими полумасками создается область разряженного давления, за счет которого в легкие сварщика попадает воздух, предварительно прошедший через фильтрующий материал. Это способно привести к попаданию вредных газов в подмасочную область по полосе обтюрации.

Эксперты рекомендуют использовать современные маски с автономными фильтрующими блоками подачи воздуха, в которых нагнетаемый вентиляторами внешний воздух поступает в очистной фильтр, а затем под щиток. Очищенный воздух подается в зону лица сварщика, что обеспечивает приток кислорода для дыхания. Вывод отработанного воздуха осуществляется через обратный клапан. Многие современные модели оснащены солнечными батареями за счет светового потока, создаваемого электрической дугой, из солнечного излучения вырабатывается энергия. Также в данных масках присутствуют оповестительные сигналы, сообщающая о нарушении работы фильтра, тем самым обеспечивают безопасность сварщика [5].

На многих предприятиях используются фильтрующие противогазы, в которых вредные вещества удаляются посредством адсорбции. Однако это не является универсальным методом защиты, так как некоторые вредные газы, в том числе и озон, свободно проходят через его фильтр. От озона, 
являющимся сильным окислителем, необходимо избавляться не адсорбцией, а химическими реакциями.

Известно, что йодистые соли способны разлагать озон, однако при этом образуется йод в больших количествах. Специалистами была создана ионообменная смола, которая способна превращать озон снова в кислород, а также поглощать йод, образовавшийся при этом. На основе этой смолы Центральный научно-исследовательский институт технологии судостроения разработал специальный аппарат, который способен функционировать без замены ионообменных фильтров боле 700 ч [6].

\section{Выводы}

1. Установлено, что одним из опасных факторов, возникающих при сварке, является выделение озона, которое наблюдается в особо высоких концентрациях при сварках вида TIG, MAG.

2. Для эффективной защиты от вредного воздействия озона разработаны различные средства защиты, которые успешно применяются в сварочных процессах. Одним из широко используемых видов СИЗОД являются современные маски с автономными фильтрующими блоками подачи воздуха, а также с ионообменной смолой.

3. Высококвалифицированный сварщик является ценным сотрудником, работоспособность и здоровье которого должно быть в приоритете у работодателя, так как сварщики подвержены воздействиям вредных факторов в течение более 70 \% времени рабочей смены. Однако после проведенного опроса среди сварщиков, работающих на различных предприятиях, было установлено, что на большинстве этих предприятий не уделяется должного внимания использованию респираторов и других средств защиты органов дыхания. На наш взгляд, важно отметить факт того, что у учащихся колледжей по профессии «Сварщик» не формируется понимание необходимости в данной защите, так как они, по результатам 
наших опросов, практически не используют защитные маски и респираторы в процессе выполнения сварочных работ.

\section{Список используемых источников}

1. Кусраева 3.С. Оценка профессионального риска при современных методах электродуговой сварки и резки металлов: дис. ... канд. мед. наук. СПб.: СПбГМУ, 2011. 25 с.

2. Назаров А.К. Теоретические основы безопасности жизнедеятельности. М.: ДЭФА, 2000. 120 с.

3. Гришагин В.М. Сварочный аэрозоль: образование, исследование, локализация, применение. Томск.: Изд-во Томского политехн. ун-та, 2011. 213 c.

4. Степанова М., Цыбин В. Измерение концентрации озона во время сварочных работ // Клинский институт охраны и условий труда. 03.02.2020. URL: https://www.kiout.ru/info/publish/26597 (дата обращения: 05.09.2020).

5. Как обеспечить защиту органов дыхания сварщика // Охрана труда и пожарная безопасность. 30.01.2019. URL: https://otpb.com.ru/news/kakobespechit-zashchitu-organov-dyhaniya-svarshchika (дата обращения: 20.09.2020).

6. Евдокимов Ю.А., Сафиулин Н.С. Разработка средств индивидуальной защиты от озона на основе новых материалов и технологий // Вестник технологии судостроения. 1999. № 5. С. 89-91.

\section{References}

1. Kusraeva Z.S. Otsenka professional'nogo riska pri sovremennykh metodakh elektrodugovoi svarki i rezki metallov: dis. kand. med. Nauk [Assessment of professional risk in modern methods of electric arc welding and cutting of metals: Cand. Med. Sci. Diss.]. Saint Petersburg, SPbGMU Publ., 2011. 25 p. [in Russian]. 
2. Nazarov A.K. Teoreticheskie osnovy bezopasnosti zhiznedeyatel'nosti [Theoretical Foundations of Security life activity]. Moscow, DEFA Publ, 2000.120 p. [in Russian].

3. Grishagin V.M. Svarochnyi aerozol': obrazovanie, issledovanie, lokalizatsiya, primenenie [Welding fumes: education, research, localization, application]. Tomsk, Izd-vo Tomskogo politekhn. un-ta, 2011. 213 p. [in Russian].

4. Stepanova M., Tsybin V. Izmerenie kontsentratsii ozona vo vremya svarochnykh rabot [Measurement of ozone concentration during welding]. Klinskii institut okhrany $\mathrm{i}$ uslovii truda. 03.02.2020. Available at: https://www.kiout.ru/info/publish/26597 (accessed 05.09.2020). [in Russian].

5. Kak obespechit' zashchitu organov dykhaniya svarshchika [How to protect the welder's respiratory system]. Okhrana truda i pozharnaya bezopasnost'. 30.01.2019. Available at: https://otpb.com.ru/news/kak-obespechit-zashchituorganov-dyhaniya-svarshchika (accessed 20.09.2020). [in Russian].

6. Evdokimov Yu.A., Safiulin N.S. Razrabotka sredstv individual'noi zashchity ot ozona na osnove novykh materialov i tekhnologii [Development of personal protective equipment against ozone based on new materials and technologies]. Vestnik tekhnologii sudostroeniya - Shipbuilding Technology Bulletin, 1999, No. 5, pp. 89-91. [in Russian].

\section{Сведения об авторах}

\section{About the authors}

Султанова Гузель Азаматовна, студент кафедры «Транспорт и хранение нефти и газа», УГНТУ, г. Уфа, Российская Федерация

Guzel A. Sultanova, Student of Transport and Storage of Oil and Gas Department, USPTU, Ufa, Russian Federation

e-mail: sultanova_guzel00@mail.ru 
Кинев Сергей Анатольевич, канд. техн. наук, доцент кафедры «Оборудование и технологии сварки и контроля», УГНТУ, г. Уфа, Российская Федерация

Sergey A. Kinev, Candidate of Engineering Sciences, Assistant Professor of Equipment and Technologies for Welding and Control Department, USPTU, Ufa, Russian Federation

e-mail: kinev@rusoil.net

Файрушина Валерия Рустемовна, студент кафедры «Оборудование и технологии сварки и контроля», УГНТУ, г. Уфа, Российская Федерация

Valeriya R. Fairushina, Student of Equipment and Technologies for Welding and Control Department, USPTU, Ufa, Russian Federation

e-mail: otsk@rusoil.net 